\title{
Mathematical Representation, Modeling and Linearization for Fixed Wing UAV
}

\author{
Eslam Nabil Mobarez \\ Ain Shams University \\ Egypt \\ Cairo
}

\author{
A. N. Ouda \\ Military technical college \\ Egypt \\ Cairo
}

\author{
Abdelhalim Abdelnabi \\ Zekry \\ Ain Shams University \\ Egypt \\ Cairo
}

\begin{abstract}
The UAV is an acronym for Unmanned Aerial Vehicle, which is an aircraft without pilot on board. UAVs can be remote controlled by a pilot at a ground control station or can fly autonomously base on pre-programmed flight plans or more complex dynamic automation systems. Technology advancements have enabled the development of it to do many excellent jobs as reconnaissance, surveillance, battle fighters, and communications relays. Simulating an unmanned aerial vehicle (UAV) dynamics and analyzing its behavior at the preflight stage is too important and more efficient. In this paper, shows a mathematical modeling of the aircraft and derivation full non-linear equations of motion on modeling technique (Ultrastick-25e) and then the linearized airframe transfer function is derived in longitudinal and lateral plane via two synthesis, Jacobin and analytical manipulation from the derived equation of motion.

And show the validation of analytical linearization transfer function with Jacobin and nonlinear model in each lateral and longitudinal channel.
\end{abstract}

\section{Keywords}

Mathematical modeling; Equations of motion; analytical and Jacobin linearization; modeling; nonlinear model; validation; UAV

\section{INTRODUCTION}

Understanding the dynamical response of an aircraft to the movement of its control surfaces is essential for designing an aircraft flight control system. This understanding requires flight testing of the aircraft, and because of the high cost of building and flight testing a real aircraft, the importance of aircraft mathematical models goes far beyond control system design. The main topic in this paper is linearization of equations when the various flight conditions, on other hand, several researches were worked on the straight and level condition only, and few researchers was solved the analytical linearization in lateral channel only on (ultrastick-25e) model [8]. But in this paper solved analytical linearization in lateral and longitudinal channel and linearized the equation at different flight conditions. This paper is organized beginning with introduction section and the other sections are arranged as follows.

$2^{\mathrm{n}} \mathrm{d}$ section, reference frame and coordinates transformation, and Building the aircraft mathematical model requires the knowledge of how the aerodynamic forces and moments acting on an aircraft are created, how they are modeled mathematically, and how the data for the models are gathered. Consequently, the equations of aircraft's motion and its control systems must be completely understood in this paper.

The 3rd section, describes in detail the UAV simulation nonlinear model (force and moment model.6degree of freedom model, environmental data model, auxiliary equation model).The UAV Simulation model is written in the Matlab/Simulink environment using the Aerospace Block set. Three simulation environments are maintained: a basic nonlinear simulation, a linear model.

The 4th section, steady state trimmed flight in different scenarios and states solution of aircraft modeling and Separation of the equations of aircraft motion.

At last section, analytical linearization of aircraft equations of motion in lateral (roll dynamics) and longitudinal (pitch dynamics) and the validation of the obtained linearized model is obtained.

\section{MATIMATICAL MODELING}

To describe the motion of an aircraft, it is necessary, first, to define the following coordinate Systems for formulation of the equations of motion as in figure (1).

A. frames and coordinates transformation [1]

- $\quad$ Earth axis system:

- Aircraft-Body coordinate frame

- $\quad$ Stability axis system

- $\quad$ North-East-Down (NED) frame

The corresponding transformation matrices using the direction cosines technique are obtained in reference as follows

$\mathrm{B}=\mathrm{B} \psi \mathrm{B} \theta \mathrm{B} \emptyset$

$\mathrm{B}=\left[\begin{array}{ccc}C \psi C \theta & S \psi C \theta & -S \theta \\ C \psi S \theta S \varnothing-S \psi S \varnothing & S \psi S \theta S \varnothing+C \psi C \emptyset & C \theta S \varnothing \\ C \psi S \theta C \emptyset+S \psi S \varnothing & S \psi S \theta S \varnothing-C \psi S \varnothing & C \theta C \varnothing\end{array}\right]$

Where

$\mathrm{Ci}$ represents cos (i)

$\mathrm{Si} \quad$ represents $\sin (\mathrm{i})$ 


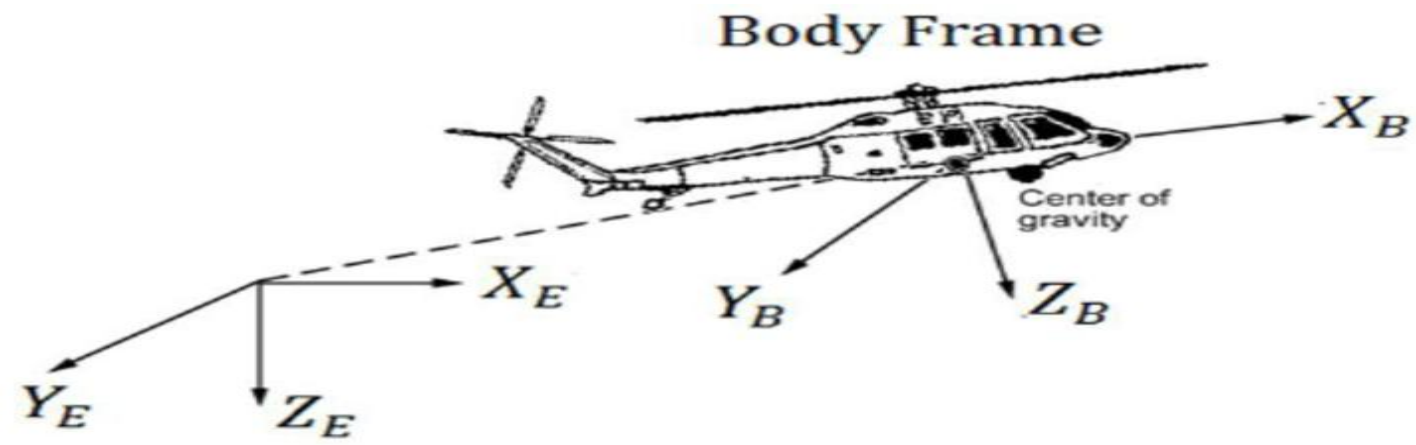

Earth Frame

Fig 1: the rotational frames

\subsection{Basic aerodynamics}

The aerodynamic forces and moments on an aircraft are produced by the relative motion with respect to the air and

depend on the orientation of the aircraft with respect to the airflow. there are two orientation angles needed to specify the aerodynamic forces and moments, these angles are the Angle Of Attack $(\alpha)$ and the Sideslip Angle (B), and are known as the aerodynamic angles. The forces and moments acting on the aircraft are defined in terms of the aerodynamic angles. Dimensionless aerodynamic coefficients and the flight dynamic pressure as follows:

$$
\begin{aligned}
& \text { Axial force } \mathrm{X}=\bar{q} \mathrm{~S} \mathrm{Cx}=1 / 2 \rho \mathrm{V}^{2} \mathrm{~S} \mathrm{Cx} \\
& \text { Side force } \mathrm{Y}=\bar{q} \mathrm{~S} \text { Cy }=1 / 2 \rho \mathrm{V}^{2} \mathrm{~S} \text { Cy } \\
& \text { Normal force } Z=\bar{q} S C Z=1 / 2 \rho V^{2} S C z \\
& \text { Rolling force } \mathrm{L}=\bar{q} \mathrm{~S} C L=1 / 2 \rho \mathrm{V}^{2} \mathrm{~S} \mathrm{~B} \mathrm{CL} \\
& \text { Pitching force } \mathrm{M}=\bar{q} \mathrm{~S} C \mathrm{CM}=1 / 2 \rho \mathrm{V}^{2} c \mathrm{~S} \quad \mathrm{CM}_{\mathrm{M}} \\
& \text { Yawing force } \mathrm{N}=\bar{q} \mathrm{~S} C N=1 / 2 \rho \mathrm{V}^{2} \mathrm{~S} B \mathrm{CN}_{\mathrm{N}}
\end{aligned}
$$

\subsection{Forces and moments acting on aircraft}

The external forces and moments acting on the aircraft can be re-expressed as:

$$
\begin{aligned}
& \mathrm{X}=\mathrm{FX}+\mathrm{GX}+\mathrm{XT} \\
& \mathrm{Y}=\mathrm{FY}+\mathrm{GY}+\mathrm{YT} \\
& \mathrm{Z}=\mathrm{FZ}+\mathrm{GZ}+\mathrm{ZT} \\
& \mathrm{L}=\mathrm{MX}+\mathrm{LT} \\
& \mathrm{M}=\mathrm{MY}+\mathrm{MT} \\
& \mathrm{N}=\mathrm{MZ}+\mathrm{NT}
\end{aligned}
$$

For convenience, $\mathrm{X}, \mathrm{Y}, \mathrm{Z}$ will contain implicitly the propulsive force components, also L, M, N will contain implicitly the propulsive moment components, so the nonlinear equations of motions are obtained as follows:

$$
\begin{aligned}
& \mathrm{X}-\mathrm{mg} \sin \theta=\mathrm{m}(\dot{\mathrm{U}}+\mathrm{q} \mathrm{W}-\mathrm{V} \mathrm{r}) \\
& \mathrm{Y}+\mathrm{mg} \cos \theta \sin \emptyset=\mathrm{m}(\dot{\mathrm{V}}+\mathrm{U} \mathrm{r}-\mathrm{P} \mathrm{W}) \\
& \mathrm{Z}+\mathrm{mg} \cos \theta \cos \emptyset=\mathrm{m}(\dot{\mathrm{W}}+\mathrm{V} \mathrm{P}-\mathrm{U} \mathrm{q}) \\
& \mathrm{L}=\mathrm{Ixx} \dot{\mathrm{P}}-\mathrm{Ixz}(\dot{\mathrm{r}}+\mathrm{P} \mathrm{q})+(\mathrm{Izz}-\mathrm{Iyy}) \mathrm{P} \mathrm{r} \\
& \mathrm{M}=\mathrm{Iyy} \dot{\mathrm{q}}+\mathrm{Ixz}\left(\mathrm{P}^{2}-\mathrm{r}^{2}\right)+(\mathrm{Ixx}-\mathrm{Izz}) \mathrm{P} \mathrm{r}
\end{aligned}
$$

$\mathrm{N}=\mathrm{Izz} \dot{\mathrm{r}}-\mathrm{Ixz} \dot{\mathrm{p}}+\mathrm{P} \mathrm{q}(\mathrm{Iyy}-\mathrm{Ixx})+\mathrm{Ixz} \mathrm{q} \mathrm{r}$

\subsection{Gravitational and thrust forces}

The gravitational force acts at the center of gravity of the aircraft. In the aircraft, the centers of mass and gravity coincide so there is no external moment produced by gravity about the c.g. direct resolution of the vector $\mathrm{mg}$ along the coordinate system axes $(\mathrm{x}, \mathrm{y}, \mathrm{z})$ yields the following components:

$$
\begin{aligned}
\mathrm{Gx} & =-\mathrm{mg} \sin \theta \\
\mathrm{Gy} & =\mathrm{mg} \cos \theta \sin \varnothing \\
\mathrm{Gz} & =\mathrm{mg} \cos \emptyset \cos \theta
\end{aligned}
$$

\subsection{Kinematic equations}

$\dot{\emptyset}=\mathrm{P}+\dot{\psi} \sin \theta$

$\dot{\psi}=\mathrm{q} \frac{\sin \emptyset}{\cos \theta}+\mathrm{r} \frac{\cos \emptyset}{\cos \theta}$

$\dot{\theta}=\mathrm{q} \cos \emptyset-\mathrm{r} \sin \varnothing$

\subsection{Navigation equations}

In the Earth reference axis system, the position of the aircraft c.g is represented by the inertial position vector P0 (t). The transformation matrix $\mathrm{B}(\mathrm{t})$ that takes vectors from the Earth reference frame to the body frame is given by $\mathrm{Eq}(1)$. Since the Earth reference frame and body frame are orthogonal and the transformation is a pure rotation, then the B matrix is an orthogonal matrix and consequently its transpose ( $\left.\mathrm{B}^{\prime}\right)$ is equal to its inverse. Therefore, the absolute velocity of aircraft c.g in Earth reference frame is given by:

$\dot{\mathrm{P}_{0}}=\dot{\mathrm{B}}\left[\begin{array}{c}\mathrm{U} \\ \mathrm{V} \\ \mathrm{W}\end{array}\right]$

The three components of the inertial position vector $\mathrm{P} 0$ are given as follows:

$\dot{P} n=U \cos \theta \cos \psi+V(-\cos \emptyset \sin \psi+\sin \emptyset \sin \theta \cos \psi)$ $+W(\sin \emptyset \sin \psi+\cos \emptyset \sin \theta \cos \psi)$

$\dot{P e}=U \cos \theta \sin \psi+V((\cos \emptyset \cos \psi+\sin \emptyset \sin \theta \sin \psi)$ $+W(-\sin \emptyset \cos \psi+\cos \emptyset \sin \theta \sin \psi)$

$\dot{h}=U \sin \theta+V \cos \theta \sin \emptyset+W \cos \theta \cos \emptyset-r \sin \emptyset=$ $\dot{\theta} \sin ^{2} \emptyset-\dot{\psi} \cos \theta \sin \emptyset \cos \emptyset$ 


\section{MODELING OF UAV}

The different modules constituting the aircraft model are coupled to each other as shown in the following Figure (2). The input data to the block diagram of the aircraft model includes:
The four control inputs which are the elevator $\delta$ e, the ailerons $\delta \mathrm{a}$, the rudder $\delta \mathrm{r}$ deflections in degrees and the throttle input $\delta \mathrm{t}$ in the range of zero to 1 .

The state variables are used for computing the aerodynamic forces and moments, and hence the force, moment, kinematics and navigationequation

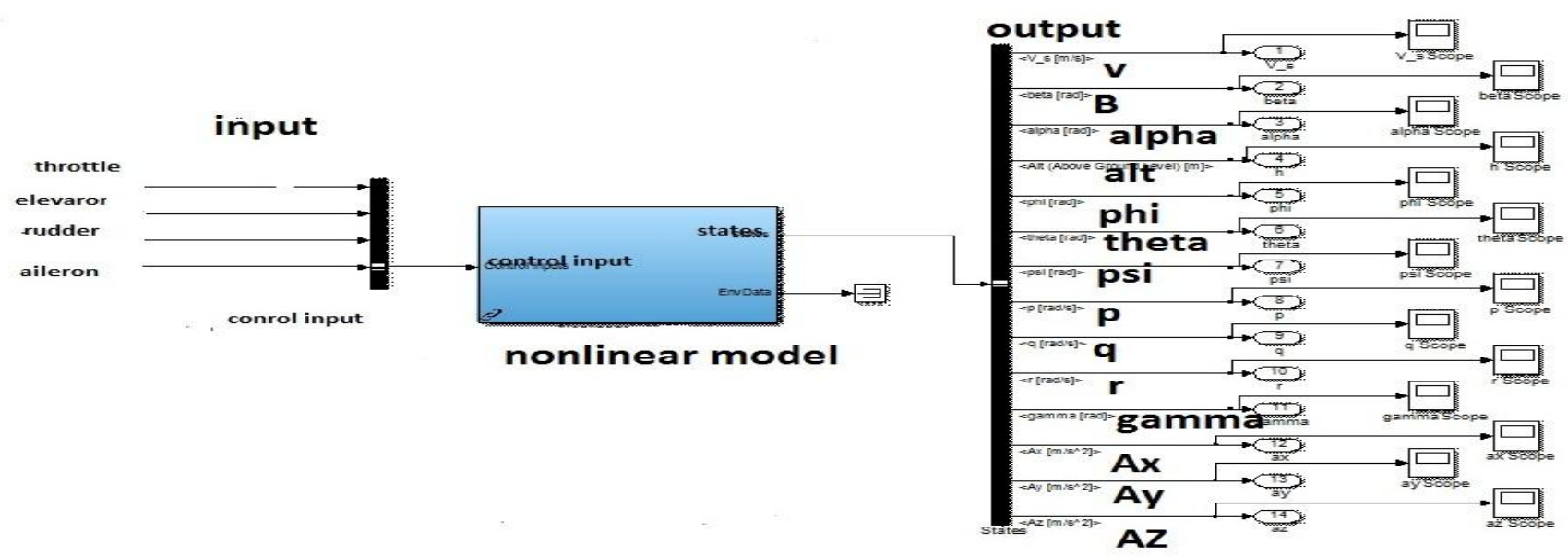

Fig 2: nonlinear model

\subsection{Nonlinear Simulation}

The nonlinear simulation has the Nonlinear UAV Model only (no actuators or sensor models) as figure (2). Top level inputs and outputs are used for generating and storing trim conditions and linear models. The trim condition generated with this model is used for the other simulations. The aircraft configuration, trim condition, and linear models are stored in the Libraries directory. This library is the primary plant dynamics block that is shared between the simulation environments. The majority of this block is simply links to other libraries. Inputs to this block are the Control Inputs bus; Outputs are the State and Environmental Data busses. This block is a masked subsystem; the parameter inputs are initial states and parameters for the equations of motion (EOM), navigation, propulsion, and aerodynamic models as in figure (3)

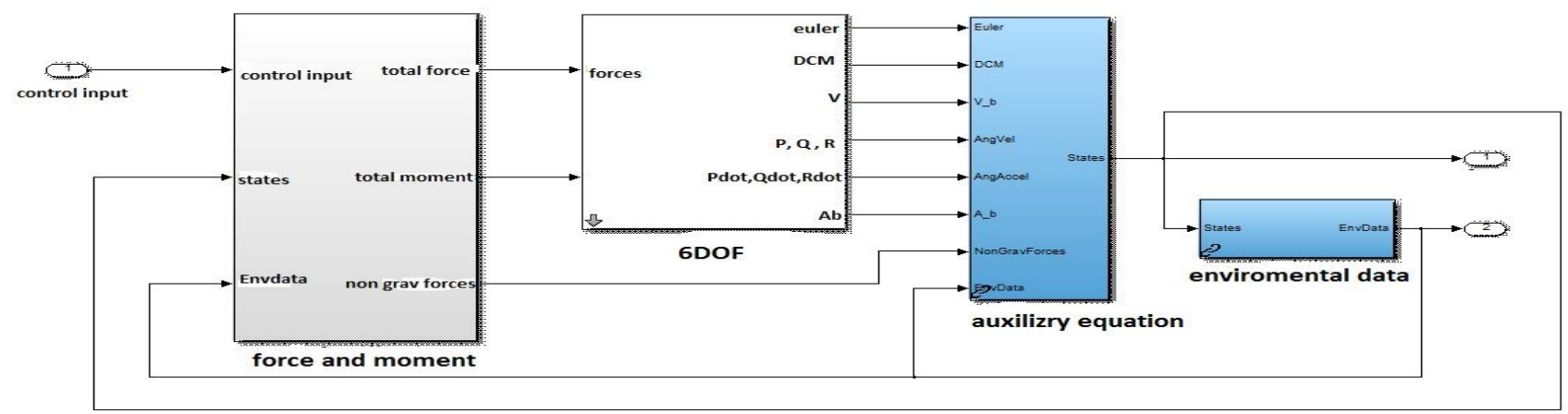

Fig 3: nonlinear blocks

\subsubsection{Forces and moments}

This subsystem contains library links and block interconnections to the three main force and moment models: Aerodynamic, Gravity, and Propulsion. One important note is the Aerodynamic model is a Configurable Subsystem to allow switching between aero models.

the inputs to this subsystem are the Control Inputs, States, and Environmental Data buses. Outputs are Total Force, Total Moment, and non Gravitational Forces. The non Gravitational Forces are used to calculate accelerometer sensor readings.

\subsubsection{Auxiliary equations.}

This block is a library link that contains additional equations to compute parameters of interest from the aircraft state vector. This block also creates the States output bus. Important components of this block are the integration of winds and turbulence, navigation equations; wind axes parameters, and Euler angle rates. Navigation.

\subsubsection{Environment.}

This block is a library link that contains the environmental model as figure (4). The COESA Atmosphere Model from the Aerospace Block set is used for air temperature, speed of sound, pressure, and density. The Winds block is a configurable subsystem, as is the Magnetic Model.

\subsection{Nonlinear closed loop simulation.}

This simulation includes the plant dynamics, actuators, sensors, time delays, and the flight controller C-code in a MEX-function, as shown in the following figure (5).

\subsubsection{Actuators.}

This block as figure (6) is a library link that contains first order; rate and position limited actuator servo models. 
Actuator parameters are set in the aircraft-specific m-files. Currently the ailerons and elevator and rudder are modeled as a single actuator and no flap actuators are modeled.

\subsubsection{Sensors.}

This block is a library link that models sensor noise, bias, and scale factor errors. These effects are modeled for the IMU sensor (angular rate, accelerations, magnetic field) and the air data system (airspeed and altitude).

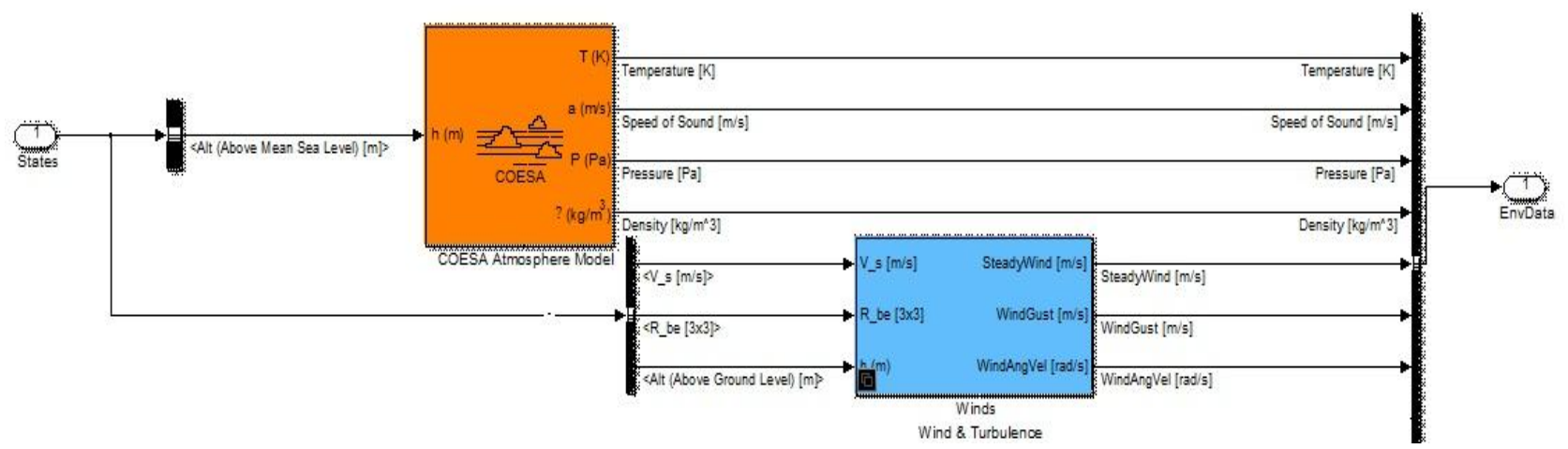

Fig 4: Environmental model

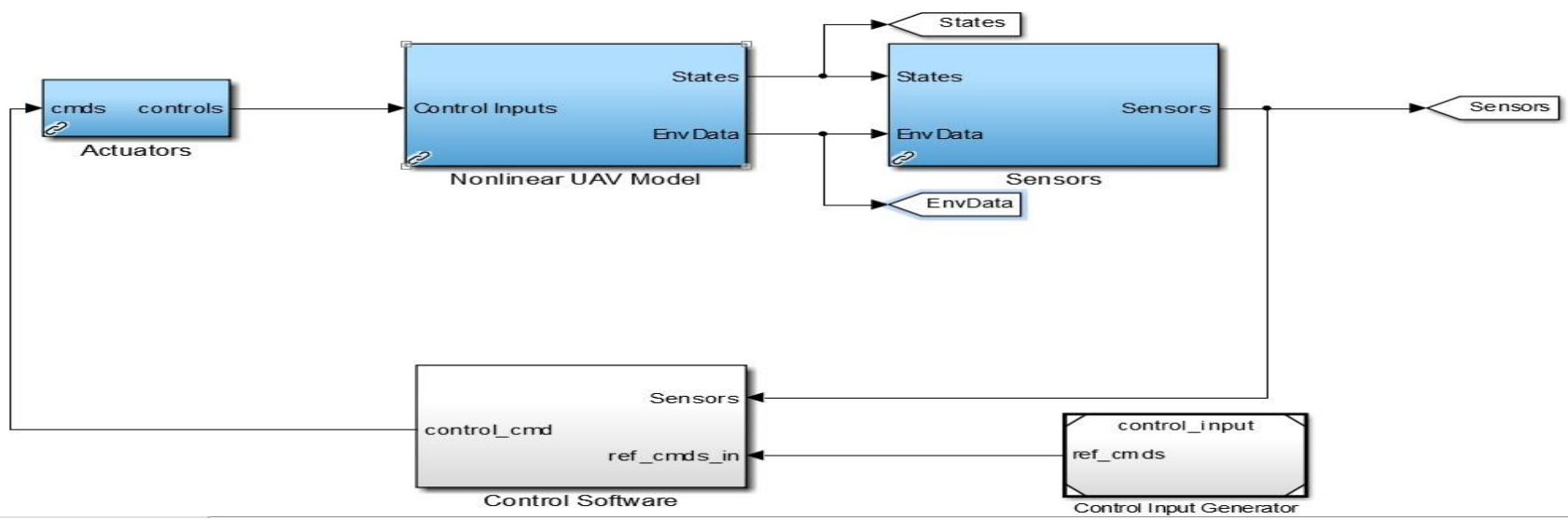

Fig 5: Nonlinear closed loop simulation

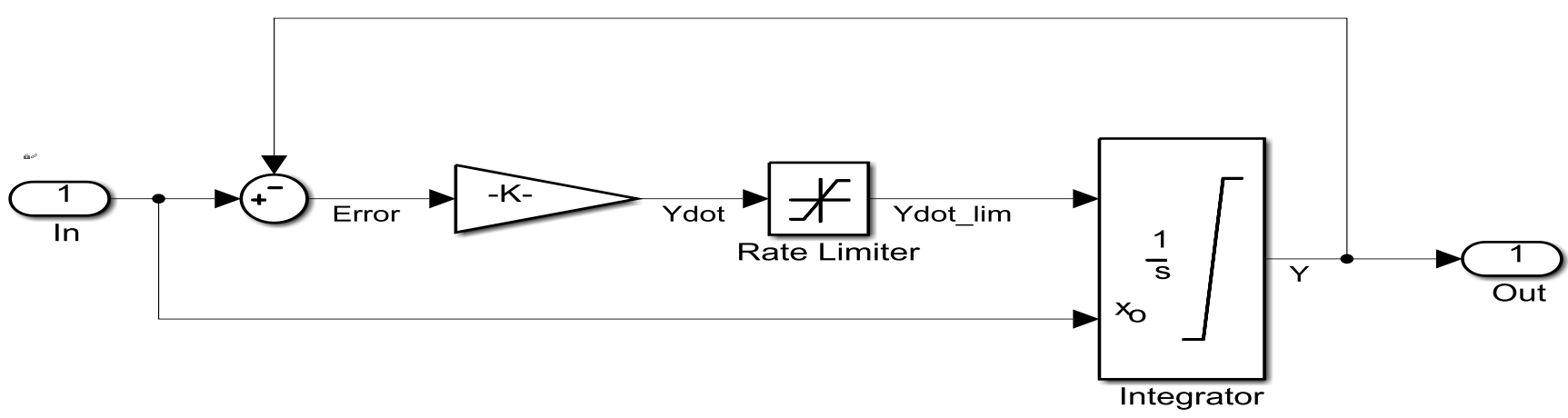

Fig 6: Actuators

\section{STEADY STATE TRIMMED FLIGHT}

Steady-state aircraft flight can be defined as the condition in which all of the motion variables are constant or zero. That is, linear and angular velocities components are constant (or zero), and all acceleration components are zero. This definition is very restrictive unless the aircraft mass is assumed to be constant. This definition allows steady wingslevel flight and steady turning flight. If the change in atmospheric density with altitude is neglected, a wings-level climb and a climbing turn are permitted as steady-state flight conditions. Steady-state flight conditions are as follows:

\section{$\dot{\mathrm{P}}, \dot{\mathrm{q}}, \dot{\mathrm{r}}, \dot{\mathrm{U}}, \dot{\mathrm{V}}, \dot{\mathrm{W}}, \dot{\mathrm{V} t}, \dot{\alpha}, \dot{\beta}=0 \quad \mathrm{U}=\mathrm{CONSTANT}$}

In addition, the following constraints can be considered according to the flight condition as figure (7):
1- straight and level $\varnothing \dot{\varnothing}, \dot{\theta}, \dot{\psi} \cong 0$
$\mathrm{P}, \mathrm{q}, \mathrm{r}=0$
2- level climb $\emptyset, \dot{\emptyset}, \dot{\psi} \cong 0$
$\dot{\theta}=$ pull - up rate 
3- level, turn $\phi, \dot{\theta} \cong 0 \quad \dot{\psi}=$ turn rate

4- climbing turn $\varnothing \dot{\varnothing}=0 \dot{\theta}, \dot{\psi}=$ pull - up rate\& Turn rate

5- level steady heading sideslip $\emptyset \dot{\emptyset}, \dot{\theta}, \dot{\psi} \cong 0 \quad \dot{\beta}=$ side slip angle
Operating point specifications were successfully met.

States: $\{\varnothing \theta \psi \mathrm{P}$ q r U V W Xe Ye Ze $\omega\}$ Control input $\{\delta$ throttle, $\delta$ elevator $\delta$ rudder $\delta$ aileron $\}$

Output : $\{$ VT $\beta \alpha \mathrm{h} \gamma \emptyset \theta \psi \mathrm{P}$ Q R ax ay az $\}$

flight condition (differnt scenarios)

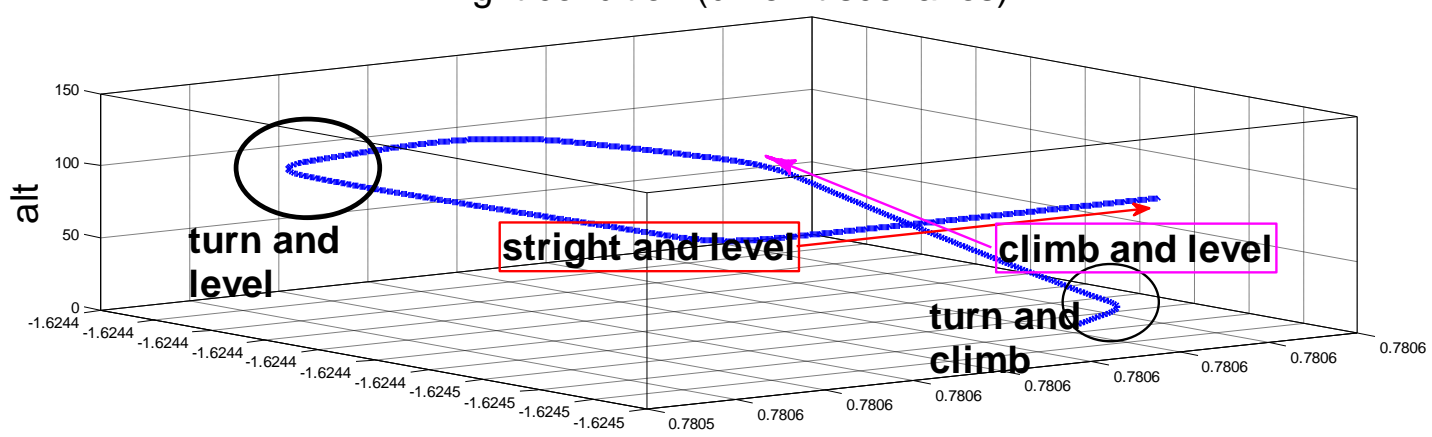

lat

Ion

Fig 7: flight path

Table1. Trim results for operating point: $\mathrm{V}=17[\mathrm{~m} / \mathrm{s}], \mathrm{H}=100[\mathrm{~m}]$ straight and level

\begin{tabular}{|c|c|c|c|c|c|c|c|c|}
\hline Input & \multicolumn{4}{|c|}{ States } & \multicolumn{4}{|c|}{ Output } \\
\hline Throttle $=0.57$ & $\emptyset=-0.00172$ & $\mathrm{Q}=6.08 \mathrm{e}-23$ & $\mathrm{~W}=0.914$ & $\omega=827$ & $\mathrm{Vt}=17$ & $\gamma=-9.8^{*} 10^{\wedge}-17$ & $\mathrm{P}=6.57 \mathrm{e}-26$ & $\mathrm{Ay}=0.016$ \\
\hline Elevator $=0.096$ & $\theta=0.0538$ & $R=-6.36 e-26$ & $\mathrm{Xe}=2.07 \mathrm{e}-15$ & & $\beta=-1.3^{*} 10^{\wedge}-22$ & $\varnothing=-0.001$ & $\mathrm{Q}=6.08 \mathrm{e}-23$ & $\mathrm{Az}=-9.79$ \\
\hline Aileron $=0.0031$ & $\psi=1.57$ & $\mathrm{U}=17$ & $\mathrm{Ye}=-6.59 \mathrm{e}-16$ & & $\alpha=0.0538$ & $\theta=0.0538$ & $R=-6.3 e-26$ & \\
\hline Rudder $=0$ & $\mathrm{P}=6.57 \mathrm{e}-26$ & $\mathrm{~V}=-2.33 \mathrm{e}-21$ & $\mathrm{Ze}=-100$ & & $\mathrm{H}=70.8$ & $\psi=1.57$ & $\mathrm{Ax}=0.527$ & \\
\hline
\end{tabular}

Table2. Trim results for operating point: $\mathrm{V}=17[\mathrm{~m} / \mathrm{s}], \gamma=5$ [degree] level and climb

\begin{tabular}{|c|c|c|c|c|c|c|c|c|}
\hline Input & \multicolumn{3}{|c|}{ States } & \multicolumn{3}{c|}{ Output } \\
\hline Throttle=0.721 & $\varnothing=-0.00239$ & $\mathrm{Q}=-4.08 \mathrm{e}-26$ & $\mathrm{~W}=0.899$ & $\begin{array}{c}\omega=89 \\
0\end{array}$ & $\mathrm{Vt}=17$ & $\gamma=0.0873$ & $\mathrm{P}=2.85 \mathrm{e}-26$ & $\mathrm{Ay}=0.023$ \\
\hline Elevator=-0.102 & $\theta=0.14$ & $\mathrm{R}=3.08 \mathrm{e}-28$ & $\mathrm{Xe}=6.97 \mathrm{e}-13$ & & $\beta=-1.7^{*} 10^{\wedge}-25$ & $\varnothing=-0.00239$ & $\mathrm{Q}=-4.0 \mathrm{e}-26$ & $\mathrm{Az}=-9.71$ \\
\hline Aileron=0.0043 & $\psi=2.71$ & $\mathrm{U}=17$ & $\mathrm{Ye}=1.05 \mathrm{e}-12$ & & $\alpha=0.0529$ & $\theta=0.14$ & $\mathrm{R}=-6.3 \mathrm{e}-26$ & \\
\hline Rudder=0 & $\mathrm{P}=2.85 \mathrm{e}-29$ & $\mathrm{~V}=-2.99 \mathrm{e}-24$ & $\mathrm{Ze}=-100$ & & $\mathrm{H}=70.8$ & $\psi=2.71$ & $\mathrm{Ax}=1.37$ & \\
\hline
\end{tabular}

Table3. Trim results for operating point: $V=17[\mathrm{~m} / \mathrm{s}], \dot{\psi}=20[$ degree] level and turn

\begin{tabular}{|l|l|l|l|l|l|l|l|l|}
\hline \multicolumn{1}{|c|}{ Input } & \multicolumn{3}{c|}{ States } & \multicolumn{3}{c|}{ Output } \\
\hline Throttle $=0.582$ & $\emptyset=-0.544$ & $\mathrm{Q}=0.181$ & $\mathrm{~W}=1.1$ & $\omega=832$ & $\mathrm{Vt}=17$ & $\boldsymbol{\gamma}=\mathbf{1 . 2 3} * \mathbf{1 0} \mathbf{0}^{-9}$ & $\mathrm{P}=-0.0193$ & $\mathbf{A y}=\mathbf{0 . 0 0 7 4 3}$ \\
\hline Elevator=-.125 & $\theta=0.0553$ & $\mathrm{R}=0.298$ & $\mathrm{Xe}=7.7 \mathrm{e}-14$ & & $\beta=-1.2^{*} 10^{\wedge}-19$ & $\emptyset=0.544$ & $\mathrm{Q}=0.181$ & $\mathrm{Az}=-11.4$ \\
\hline Aileron=0.0074 & $\psi=2.71$ & $\mathrm{U}=17$ & $\mathrm{Ye}=5.48 \mathrm{e}-12$ & & $\alpha=0.0646$ & $\theta=0.0553$ & $\mathrm{R}=0.298$ & \\
\hline Rudder=0 & $\mathrm{P}=-0.0193$ & $\mathrm{~V}=-2^{*} 10^{\wedge}-18$ & $\mathrm{Ze}=-100$ & & $\mathrm{H}=70.8$ & $\psi=2.71$ & $\mathrm{Ax}=0.74$ & \\
\hline
\end{tabular}

Table4.Trim results for operating point: $\mathrm{V}=17[\mathrm{~m} / \mathrm{s}], \gamma=5[\mathrm{deg}], \dot{\psi}=20[\mathrm{degree}]$ climbing and turn

\begin{tabular}{|l|l|l|l|l|l|l|l|l|}
\hline \multicolumn{1}{|c|}{ Input } & \multicolumn{3}{c|}{ States } & \multicolumn{3}{c|}{ Output } \\
\hline Throttle=0.731 & $\emptyset=0.547$ & $\mathrm{Q}=0.18$ & $\mathrm{~W}=1.08$ & $\omega=895$ & $\mathrm{Vt}=17$ & $\gamma=0.0873$ & $\mathrm{P}=-0.0492$ & $\mathrm{Ay}=0.0156$ \\
\hline Elevator=-.131 & $\theta=0.141$ & $\mathrm{R}=0.295$ & $\mathrm{Xe}=9.36 \mathrm{e}-13$ & & $\boldsymbol{\beta}=\mathbf{2 . 8 5} \mathbf{1 0}^{\wedge}-\mathbf{1 9}$ & $\emptyset=0.547$ & $\mathrm{Q}=0.18$ & $\mathrm{Az}=-11.3$ \\
\hline Aileron$=0.00607$ & $\psi=2.71$ & $\mathrm{U}=17$ & $\mathrm{Ye}=6.61 \mathrm{e}-13$ & & $\alpha=0.0633$ & $\theta=0.141$ & $\mathrm{R}=0.295$ & \\
\hline Rudder $=0$ & $\mathrm{P}=-0.0492$ & $\mathrm{~V}=4.8^{*} 10^{\wedge}-18$ & $\mathrm{Ze}=-100$ & & $\mathrm{H}=70.8$ & $\psi=2.71$ & $\mathrm{Ax}=1.58$ & \\
\hline
\end{tabular}

\subsection{Separation of the equations of aircraft motion}

The rigid body aircraft equations of motion could be split into two uncoupled. This decoupling occurs when the sideslip and bank angle are set to zero values. These sets are:

The Longitudinal equations that involve the variables: speed VT, angle-of-attack $\alpha$, pitch attitude $\theta$ and pitch rate $\mathrm{q}$ as states, throttle setting $\delta$ th and elevator deflection $\delta$ ele as inputs.

The Lateral equations involve the variables: sideslip angle $\beta$, roll rate $P$, yaw rate $R$, bank angle $\emptyset$, and yaw angle $\psi$ as states, ailerons deflection $\delta a$ and rudder deflection $\delta r$ as inputs. 


\subsection{Linearization of longitudinal motion.}

The characteristic equation determined from the state coefficient matrix Along, is a quadratic The longitudinaldynamics Jacobin state matrix for the ultrastick25e model in the forward-c.g. flight condition is given by:

A long $=$

\begin{tabular}{|l|l|l|l|l|l|l|}
\hline & $\mathrm{U}$ & $\mathrm{w}$ & $\mathrm{Q}$ & theta & $\mathrm{Ze}$ & Omega \\
\hline $\mathrm{U}$ & -0.5944 & 0.8008 & -0.87 & -9.79 & $5.077 \mathrm{e}-05$ & 0.0126 \\
\hline $\mathrm{W}$ & -0.7449 & -7.56 & 15.72 & -0.52 & -0.0009 & 0 \\
\hline $\mathrm{Q}$ & 1041 & -7.406 & -15.81 & 0 & $-1.30 \mathrm{e}-17$ & -0.01315 \\
\hline theta & 0 & 0 & 1 & 0 & 0 & 0 \\
\hline Ze & -0.05399 & 0.9985 & 0 & -17 & 0 & 0 \\
\hline Omega & 135.5 & 7.324 & 0 & 0 & -0.08253 & -5.903 \\
\hline
\end{tabular}

B longitudinal $=$

\begin{tabular}{|l|l|l|}
\hline & Elevator & throttle \\
\hline$U$ & 0.4669 & 0.4669 \\
\hline $\mathrm{W}$ & -2.703 & -2.703 \\
\hline $\mathrm{Q}$ & -133.7 & -133.7 \\
\hline Theta & 0 & 0 \\
\hline Ze & 0 & 0 \\
\hline Omega & 0 & 0 \\
\hline
\end{tabular}

C longitudinal $=$

\begin{tabular}{|l|l|l|l|l|l|l|}
\hline & $\mathrm{U}$ & $` \mathrm{w}$ & $\mathrm{Q}$ & Theta & Ze & Omega \\
\hline V & 0.9985 & 0.0539 & 0 & 0 & 0 & 0 \\
\hline Alpha & -0.0031 & 0.0587 & 0 & 0 & 0 & 0 \\
\hline Q & 0 & 0 & 1 & 0 & 0 & 0 \\
\hline Theta & 0 & 0 & 0 & 1 & 0 & 0 \\
\hline H & 0 & 0 & 0 & 0 & -1 & 0 \\
\hline Ax & -0.594 & 0.8008 & 0.0430 & 0 & $5.09 \mathrm{e}-05$ & 0.012 \\
\hline az & -0.744 & -7.56 & -1.256 & 0 & -0.0009 & 0 \\
\hline
\end{tabular}

D longitudinal $=$

\begin{tabular}{|l|l|l|}
\hline & Elevator & Throttle \\
\hline V & 0 & 0 \\
\hline Alpha & 0 & 0 \\
\hline Q & 0 & 0 \\
\hline Theta & 0 & 0 \\
\hline $\mathrm{H}$ & 0 & 0 \\
\hline $\mathrm{Ax}$ & 0.4669 & 0 \\
\hline $\mathrm{Az}$ & -2.703 & 0 \\
\hline
\end{tabular}

\subsection{Linearization of the lateral motion.}

The solution of the lateral equations is obtained in the same manner as the longitudinal state equations. The characteristic equation determined from the state coefficient matrix Alat yields a quintic equation

A lateral $=$

\begin{tabular}{|l|l|l|l|l|l|}
\hline & $\mathrm{v}$ & $\mathrm{p}$ & $\mathrm{r}$ & $\mathrm{psi}$ & $\mathrm{psi}$ \\
\hline $\mathrm{v}$ & -0.87 & 0.8751 & -16.82 & $5.077 \mathrm{e}-05$ & $5.077 \mathrm{e}-05$ \\
\hline $\mathrm{p}$ & -2.83 & -16.14 & 3.377 & -0.0009 & -0.0009 \\
\hline $\mathrm{r}$ & 1.701 & 0.5154 & -2.783 & 0 & 0 \\
\hline phi & 0 & 0 & 1 & $3.27^{*} 10^{\wedge}-24$ & $3.27^{*} 10^{\wedge}-24$ \\
\hline psi & 0 & 0 & 1.001 & 0 & 0 \\
\hline
\end{tabular}

B lateral $=$

\begin{tabular}{|c|c|c|}
\hline & Aileron & rudder \\
\hline $\mathrm{v}$ & 0 & 5.317 \\
\hline $\mathrm{p}$ & -156.9 & -5.022 \\
\hline
\end{tabular}

\begin{tabular}{|c|c|c|}
\hline $\mathrm{r}$ & 11.54 & -82.27 \\
\hline $\mathrm{phi}$ & 0 & 0 \\
\hline $\mathrm{psi}$ & 0 & 0 \\
\hline
\end{tabular}

C lateral $=$

\begin{tabular}{|c|c|r|r|r|r|}
\hline & $\mathrm{v}$ & $\mathrm{p}$ & $\mathrm{r}$ & Phi & $\mathrm{psi}$ \\
\hline $\mathrm{B}$ & 0.05882 & 0 & 0 & 0 & 0 \\
\hline $\mathrm{p}$ & 0 & 1 & 0 & 0 & 0 \\
\hline $\mathrm{r}$ & 0 & 0 & 1 & 0 & 0 \\
\hline $\mathrm{phi}$ & 0 & 0 & 0 & 1 & 0 \\
\hline $\mathrm{psi}$ & 0 & 0 & 0 & 0 & 1 \\
\hline
\end{tabular}

D lateral:

\begin{tabular}{|c|c|c|}
\hline & Aileron & rudder \\
\hline $\mathrm{B}$ & 0 & 0 \\
\hline $\mathrm{p}$ & 0 & 0 \\
\hline $\mathrm{r}$ & 0 & 0 \\
\hline $\mathrm{phi}$ & 0 & 0 \\
\hline $\mathrm{psi}$ & 0 & 0 \\
\hline
\end{tabular}

\section{ANALYITICAL LINEARIZATION OF AIRCRAFT EQUATION OF MOTION \\ 5.1.Analytical linearization of roll motion aircraft equations of motion}

In this section the analytical linearization of pitch and pitch dynamics can be derived to check the matching between state spaces linearized model and the analytical model.

$\dot{\theta}=\mathrm{q} \cos \emptyset-\mathrm{r} \sin \emptyset$

$\mathrm{q} \cos \emptyset=\mathrm{q}(\cos \emptyset-1)$

$\dot{\theta}=\mathrm{q}+\mathrm{q}(\cos \emptyset-1)-\mathrm{r} \sin \emptyset$

$\dot{\theta}=\mathrm{q}+\mathrm{A}$

$A=q(\cos \emptyset-1)-r \sin \emptyset$

$\ddot{\theta}=\dot{\mathrm{q}}+\dot{\mathrm{A}}$

$\alpha=\theta-\gamma$

$$
\begin{array}{r}
\ddot{\theta}=\left\lceil 5 p r-\left\lceil 6\left(r^{\wedge} 2-p^{\wedge} 2\right)+\left(1 / 2 \rho V^{\wedge} 2 S c\right) / J y(C m 0\right.\right. \\
+C m \alpha+C m \delta e+C m q c q / 2 v)+\dot{A}
\end{array}
$$

$\ddot{\theta}=27.13 \dot{\theta}-14 \theta-172 \delta \mathrm{e}$

$\mathrm{s}^{2} \theta(\mathrm{s})=27.13 \mathrm{~s} \theta(\mathrm{s})-14 \theta(\mathrm{s})-172 \delta \mathrm{e}$

$$
\theta(s)\left[s^{2}+27.13 s-14\right]=-172 \delta e
$$

the final numerical transfer function of roll $(\theta)$ for $\delta$ eas input is as:

$$
\frac{\theta}{\delta \mathrm{e}}=\frac{-172}{\mathrm{~S}^{2}+27.13 \mathrm{~S}+14}
$$

Roll rate (q) can be approximately considered as the differentiation of the pitch angle so

$$
\frac{\mathrm{q}}{\delta \mathrm{e}}=\frac{-172}{\mathrm{~s}+27.13}
$$

\subsection{Analytical linearization of roll motion aircraft equations of motion}

In this section the analytical linearization of roll and roll dynamics can be derived to check the matching between state spaces linearized model and the analytical model.

$\dot{\varphi}=\mathrm{p}+\mathrm{q} \sin \varphi \tan \theta+\mathrm{r} \cos \varphi \tan \theta$

$\ddot{\varphi}=\dot{\mathrm{p}}+\dot{\mathrm{q}} \sin \varphi \tan \theta+\mathrm{q} \cos \varphi \tan \theta+\mathrm{q} \sin \varphi \sec \theta \tan \theta+$ $\dot{\mathrm{r}} \cos \varphi \tan \theta-\mathrm{r} \sin \varphi \tan \theta+\mathrm{r} \cos \varphi \sec \theta \tan \theta$ 
$\mathrm{A}=\dot{\mathrm{q}} \sin \varphi \tan \theta+\mathrm{q} \cos \varphi \tan \theta+\mathrm{q} \sin \varphi \sec \theta \tan \theta+$ $\dot{\mathrm{r}} \cos \varphi \tan \theta-\mathrm{r} \sin \varphi \tan \theta+\mathrm{r} \cos \varphi \sec \theta \tan \theta$

$\ddot{\varphi}=\dot{p}+A$

The final numerical transfer function of roll $(\varphi)$ for $\delta a$ as input is as:

$$
\frac{\varphi}{\delta a}=\frac{-133.13}{S^{2}+15.13 S}
$$

Roll rate (p) can be approximately considered as the differentiation of the roll angle so

$$
\frac{\mathrm{p}}{\delta \mathrm{a}}=\frac{-133.13}{\mathrm{~s}+15.13}
$$

\section{VALIDATION OF AIRCRAFT MODEL LINEARIZATION}

After getting the model; some checks of the Ultrastick-25e longitudinal dynamics responses to (elevator) are illustrated in Figs. 8-9. Lateral dynamics responses to (aileron) deflections of linear Jacobin and linear analytical with nonlinear models are illustrated in Figs. 10 and 11. A doublet pulse is applied as an input signal [a pulse that is symmetric about its reference level (the trim setting) to the control input] to see the response of the various outputs.

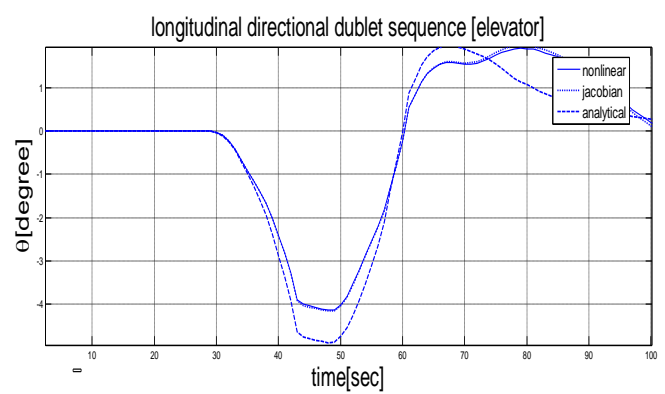

Fig 8: Linearized pitch angle comparison techniques with applying the doublet signal at the control surface $(\delta a)$

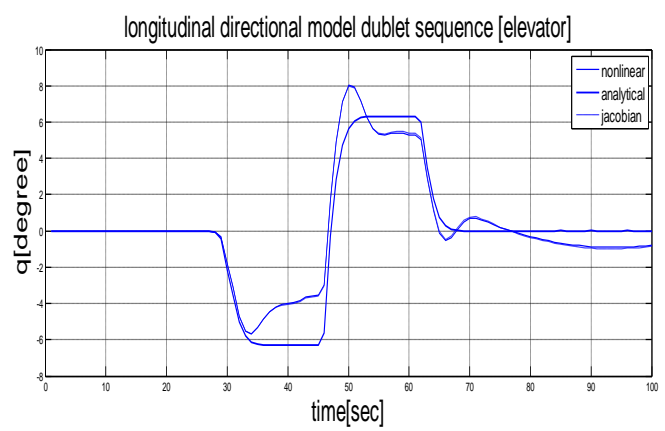

Fig 9: Linearized pitch rate comparison techniques with applying the doublet signal at the control surface $(\delta a)$

The figures $(17,18,19,20)$ show that the Comparison between the analytical linearized models and state space linearization by Jacobean matrices and the nonlinear aircraft dynamics; the figures shows agood matching between the three linearization techniques.

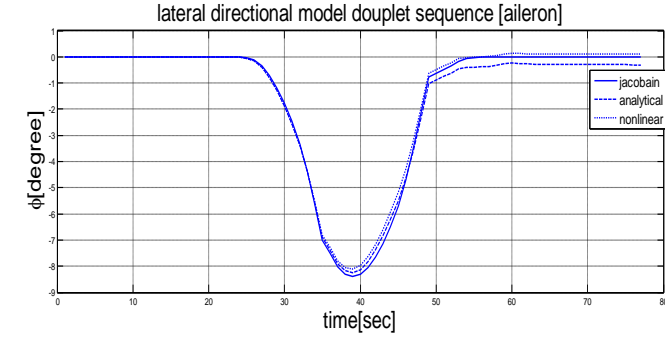

Fig 10: Linearized roll angle comparison techniques with applying the doublet signal at the control surface $(\delta a)$

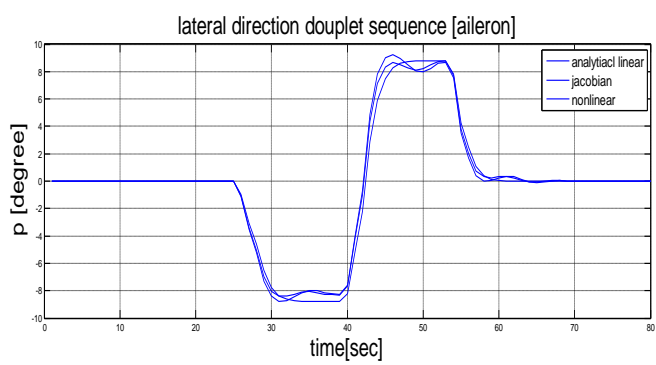

Fig 11: Linearized roll rate comparison techniques with applying the doublet signal at the control surface $(\delta a)$

\section{CONCLUSION}

Conclusions and recommendations for further research are documented in this paper. Aims of this dissertation were to carry out a comprehensive non-linear model for ultrastick-25e $\mathrm{UAV}$, to study the flight control design, and to investigate hardware in loop simulation (HILS) for the system. The proposed in progress test facility is used toward a completely autonomous UAV. To accomplish these aims, dynamical characterization of UAV associated with flight control system has been investigated.

\subsection{Ultrastick-25e UAV modeling:}

The mathematical model is derived and the aerodynamic coefficients for this model are presented. UAV sensors and actuators are discussed in view of operation principle, modeling and errors.

Obtaining 6DOF nonlinear model and, force and moment model, environmental model then linear model of ultrastick$25 \mathrm{e} U A V$. then presenting the transient analysis, of aircraft natural modes for both longitudinal and lateral motions

\subsection{Stability analysis}

The nonlinear ultrastick-25e UAV model was linearized numerically around the operating points for straight and winglevel flight condition. Decoupled linear sub models for longitudinal and lateral motions are obtained in state space form the linear aircraft model was analyzed using decomposition techniques.

validation of aircraft model linearization for lateral and longitudinal channels

The behavior of the aircraft due to the desired scenarios results were compared between the state space linearized and the derived lateral and longitudinal analytical linearized models and the nonlinear aircraft dynamics, the results is too matched between all of them, the state space linearized model can use in the design of classical controller with the trimming values of a straight and leveling scenario 


\subsection{Future work}

7.3.1. Use the obtained linearized airframe transfer function to design suitable autopilot for the underling system

7.3.2. Evaluate the designed autopilot in nonlinear environment

7.3.3. Implement the designed autopilot on the impeded system

\subsection{Nomenclature}

$\emptyset, \theta, \psi \quad$ Attitude angles, rad

$\mathrm{p}, \mathrm{q}, \mathrm{r} \quad$ Angular velocities

$\rho \quad$ Air density

$\mathrm{u}, \mathrm{v}, \mathrm{w}$ Inertial velocity components of the airframe projected onto $\mathrm{Xb}$-axis

CL Aerodynamic lift coefficient

CD Aerodynamic drag coefficient.

$\mathrm{Cm} \quad$ Aerodynamic pitch coefficient

$\mathrm{Cp} \quad$ Aerodynamic moment coefficient along thexb-axis

Cprop Aerodynamic coefficient for the propeller.

Kmotor Constant that specifies the efficiency of the motor

Sprop Area of the propeller

$\mathrm{Cq} \quad$ Aerodynamic moment coefficient along the $\mathrm{zb}$.

$\mathrm{Cx} \quad$ Aerodynamic force coefficient along $\mathrm{xb}$

Cy Aerodynamic force coefficient along yb

$\mathrm{Cz} \quad$ Aerodynamic force coefficient along $\mathrm{zb}$.

$\Gamma \quad$ Products of the inertia matrix

F the sum of external forces acting on the aircraft (aerodynamic, gravitational and propulsive).

M the sum of all applied moments.

$\mathrm{m}$ the mass of aircraft which is assumed to be constant.

$\overline{\mathrm{q}} \quad$ Dynamic pressure

S wing reference area

B wing span (length)

$c \quad$ wing mean geometric chord

V True airspeed

\section{ACKNOWLEDGMENTS}

I would like to express and present my faithful thanks and deepest gratitude to my supervisors Prof .Dr .Abdelhalim Abdelnabi Zekry and DR. Ahmed Nasr Ouda for their inestimable guidance, humongous support, admirable advising, and ceaseless encouragement.

\section{REFERENCES}

[1] Edward AFB CA, "Flying Qualities Phase. Vol2", USAF TEST Pilot School,1988.

[2] B. L. Stevens and F. L. Lewis, "Aircraft Control and Simulation", Hoboken, NJ: John Wiley\& Sons, Inc., 2nd ed., 2003.

[3] D. T. Greenwood, "Principles of Dynamics. Englewood Cliffs", NJ: Prentice Hall, 2nd ed., 1988.

[4] "USAF Stability and Control DATCOM", Flight Control Division, Air Force Flight Dynamics Laboratory, Wright- Patterson Air Force Base,Oh, 1980.

[5] Xinzhong Chen, Ahsan Kareem, "Advances in Modeling of Aerodynamic Forces on Bridge Decks", Journal of Engineering Mechanics, November 2002.

[6] Murch, A., Dorobantu, A., and Balas, G., "University of Minnesota UAV Flight Control Research Group," http://www.uav.aem.umn.edu, 4March 2013.

[7] Murch, A., Paw, Y. C. Pandita, R., Li, Z., and Balas, G., "A Low Cost Small UAV Flight Research Facility," CEAS Conference on Guidance, Navigation, and Control, Munich, Germany, 2011.

[8] A. Elsayed Ahmed, "Modeling of a Small Unmanned Aerial Vehicle," World Academy of Science, Engineering and Technology International Journal of Mechanical, Aerospace, Industrial, Mechatronic and Manufacturing Engineering Vol:9, No:3, 2015

[9] Randal W. Beard, Timothy W. Mclain, "Small Unmanned Aircraft: Theory and Practice", Princeton University Press, 2012.

[10] T. R. Beal. "Digital Simulation of Atmospheric Turbulence for Dryden and Von Karman Models", Journal of Guidance, Control, and Dynamics, Vol. 16, No. 1 (1993), pp. 132-138.

[11] R. C. Nelson, "Flight Stability and Automatic Control", Boston, MA: McGraw-Hill, 2nd ed., 1998.

[12] David A. Coughey, "Introduction to Aircraft Stability and Control", Sibley School of Mechanical \& Aerospace Engineering, Cornell University, Ithaca, New York, 2011

[13] A. Noth, S. Bouabdallah and R. Siegwart, "Dynamic Modeling of Fixed- Wing UAVs", Swiss Federal institute of technology, version 2, 2006. 